\title{
Chapter 3 \\ Menopause-Related Physiological Changes and Their Possible Control Through Diet and Exercise
}

\author{
Igor Z. Zubrzycki, Magdalena Wiacek, and Ted Greiner
}

\section{Key Points}

- Menopause is a biological aging associated phenomenon coupled with a reduction in physical fitness, and sometimes combined with emotional disturbance.

- Maintenance of as high level of physical fitness as possible, which has clear links to BMI and lipid profiles, is one of the methods of lessening these detrimental phenomena.

- Walking, its variant Nordic-walking (NW), as well as jogging, and cycling are among the most popular physical activities reducing aging- and/or menopause-associated physical fitness deterioration.

- The same advice as is given to the entire population to consume a moderate diet rich in fruits, vegetables, whole grains, legumes, and low-fat dairy products is likely to reduce some of the negative effects linked to menopause. Increased consumption of soy appears to be justified as one way to alleviate some but by no means all of these.

- Currently, Body Mass Index (BMI), serum levels of total cholesterol (TC), high-density lipoprotein (HDL-C), low-density lipoprotein (LDL-C), triglycerides (TG), blood pressure, follicle-stimulating hormone (FSH), and luteinizing hormone ( $\mathrm{LH}$ ) are often used as factors describing or linked to menopausal transition.

- Changes in systolic blood pressure (SBP) and diastolic blood pressure (DBP) during the menopausal transition are most probably solely due to age increase.

- Much of the commonly seen changes in BMI, and serum concentrations of TC, HDL-C, LDL-C, and TG are likely due to both the menopausal transition and biological age increase. However, culturally mediated changes in diet and exercise patterns at this stage in life may play a role in either worsening or protecting against these changes.

- At present, we are not able to establish clear-cut dependencies between the influence of exercise and/or diet on these specific parameters defining the menopausal transition.

I.Z. Zubrzycki, Ph.D., D.Sc. ( $ه)$

Department of Life Science, Jędrzej Śniadecki Academy of Physical Education and Sports,

ul. Kazimierza Górskiego 1, 80-336 Gdańskt, Poland

e-mail: igor@hanyang.ac.kr; igorzubrzycki@yahoo.com

M. Wiacek, Ph.D.

Jędrzej Śniadecki Academy of Physical Education and Sports, ul. Kazimierza Gorskiego 1, 80-336 Gdańskt, Poland e-mail: magdalenawiacek@yahoo.de

T. Greiner, Ph.D.

Department of Food and Nutrition, College of Human Ecology, Hanyang University,

Seongdong-gu, Wangsimni ro 222, Seoul 133-791, South Korea

e-mail: tgreiner@hanyang.ac.kr 
Keywords Menopausal transition $\bullet$ Physical exercise $\bullet$ Diet $\bullet$ Cardiovascular disease $\bullet$ Blood pressure

- Follicle-stimulating hormone $\bullet$ Luteinizing hormone $\bullet$ Aging

$\begin{array}{ll}\text { Abbreviations } \\ \text { HRQoL } & \text { Health related quality of life } \\ \text { NW } & \text { Nordic-walking } \\ \text { W } & \text { Walking } \\ \text { BMI } & \text { Body mass index } \\ \text { TC } & \text { Total cholesterol } \\ \text { TG } & \text { Triglyceride levels } \\ \text { HDL-C } & \text { High-density lipoprotein levels } \\ \text { LDL-C } & \text { Low-density lipoprotein levels } \\ \text { BP } & \text { Blood pressure } \\ \text { LH } & \text { Luteinizing hormone } \\ \text { FSH } & \text { Follicle stimulating hormone } \\ \text { CVD } & \text { Cardiovascular disease }\end{array}$

\section{Introduction}

Aging is accompanied by a variety of different factors, such as loss of postural stability, spatial orientation, and strength [1], that induce a decrease in health related quality of life (HRQoL) for both men and women. In women, however, another factor that can affect HRQoL is menopause-defined as the cessation of menstruation due to follicular depletion, resulting in a loss of ovarian sensitivity to gonadotropin stimulation. In other words, the ovaries stop producing an egg each month. During the menopausal transition, aging follicles become more resistant to gonadotropin stimulation, levels of follicle-stimulating hormone (FSH) and luteinizing hormone ( $\mathrm{LH})$ increase. The loss of functioning follicles results also in a dramatic decline in circulating estradiol during a period lasting from about 2 years before menopause to 2 years afterwards. The ups and downs of estrogen and, to a lesser extent, progesterone, probably produce most of the symptoms women experience during this transition. Serum testosterone levels do not change. Women's attitudes towards this life transition can influence its apparent impact on their health [2].

The menopausal transition begins at around 45-48 years of age and lasts several years. It is coupled with clinical symptoms and sometimes associated with emotional disturbance - perhaps exacerbated by a perceived loss of attractiveness. In Western culture, menopause has been "medicalized," implying that its symptoms may be reduced via specific preventive means [3]. This point of view has given rise to a variety of "scientifically proven" medical approaches, for example using different types of herbal ingredients all of which have either not undergone or not withstood real scientific scrutiny. However, there is one soy constituent, genistein, which may reduce the frequency and duration of hot flashes [4].

Currently we know that menopause may be accompanied by weight gain in some but not all populations [5] and an increase of vasomotor symptoms [6] resulting in a thermoregulatory imbalance. These in turn may be linked to increased adiposity-driven weight gain [6], in turn often leading to a less favorable serum lipid spectrum. Some studies have shown that total cholesterol (TC) levels, lowdensity lipoprotein cholesterol (LDL-C), high-density lipoprotein cholesterol (HDL-C), and triglyceride (TG) levels are associated not only with the aging process, per se, but also with the menopausal transition (Fig. 3.1) [7-12]. Adverse lipid profiles may be associated with a detrimentally high body mass index (BMI), which is pronouncedly associated with less increase in FSH during the menopausal transition [12] (Fig. 3.2), and with an earlier cessation of reproductive cycles. 


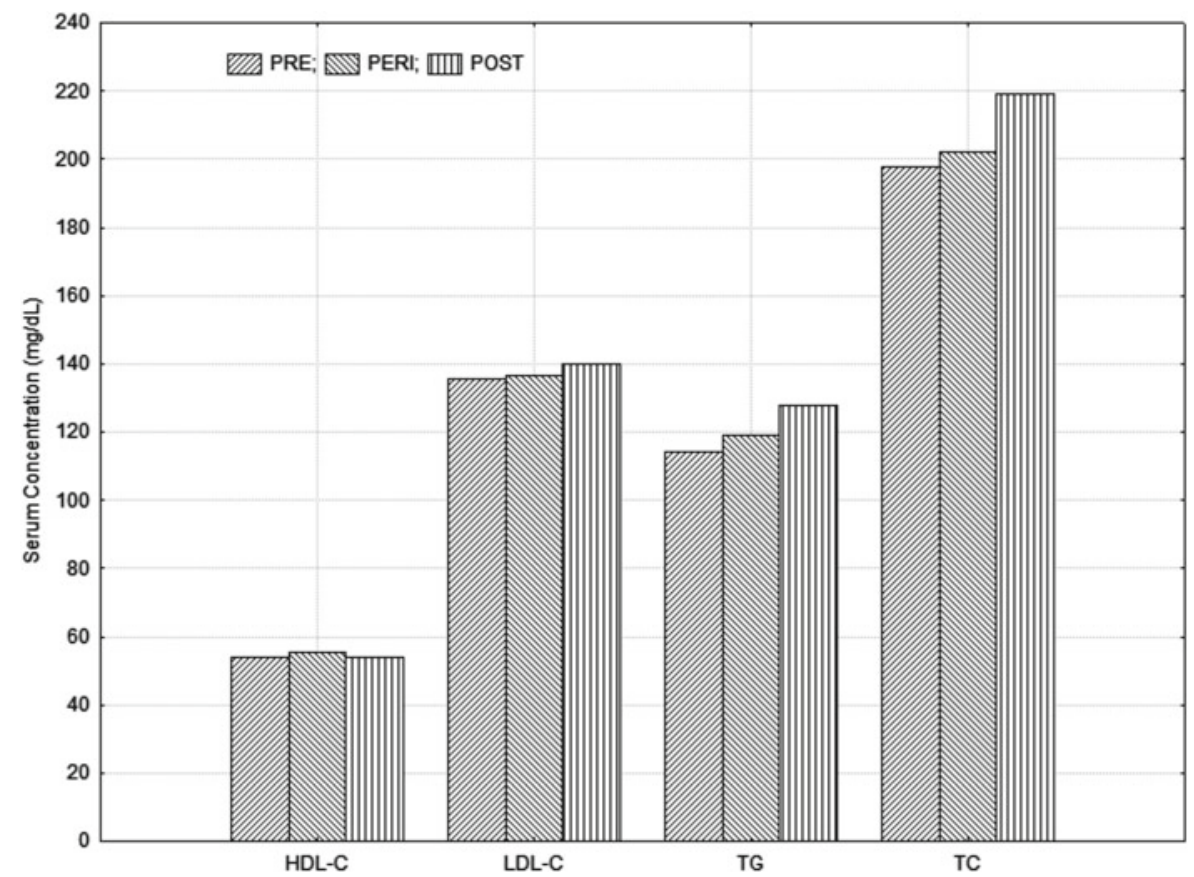

Fig. 3.1 The relationship between lipids profile and menopausal status among untrained women. The bar plot indicates menopause and/or age induced changes in serum concentration of High-density lipoprotein (HDL-C), Low-density lipoprotein (LDL-C), Triglycerides (TG), and Total Cholesterol (TC) among untrained women (after Hagner et al. [11]). For simplicity only the central values of the population are given

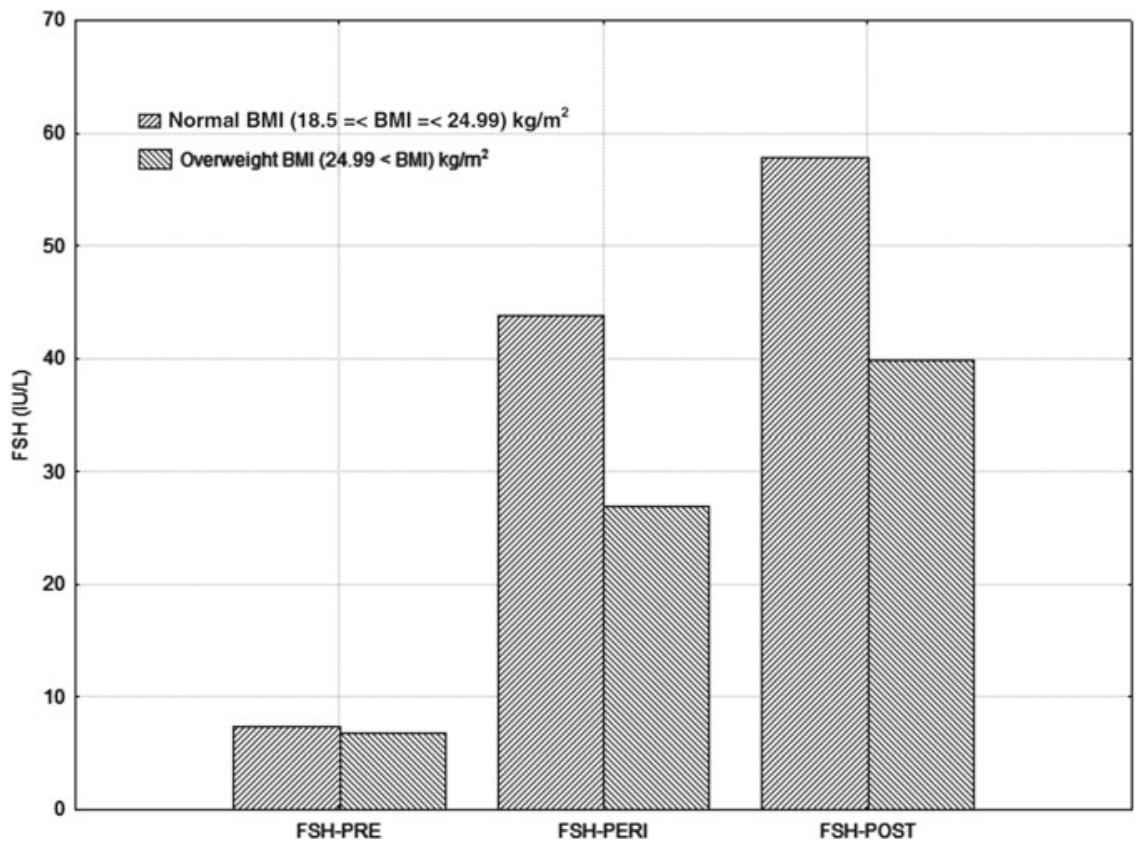

Fig. 3.2 The changes in Body Mass Index and FSH and LH activity as a function of menopausal status. The bar plot indicates relation between Body Mass Index (BMI; $\mathrm{kg} / \mathrm{m}^{2}$ ) and activity of Follicle Stimulating Hormone (FSH; IU/L) in premenopausal, perimenopausal, and postmenopausal women (after Wiacek et al. [12]). For simplicity only the central values of the population are given 


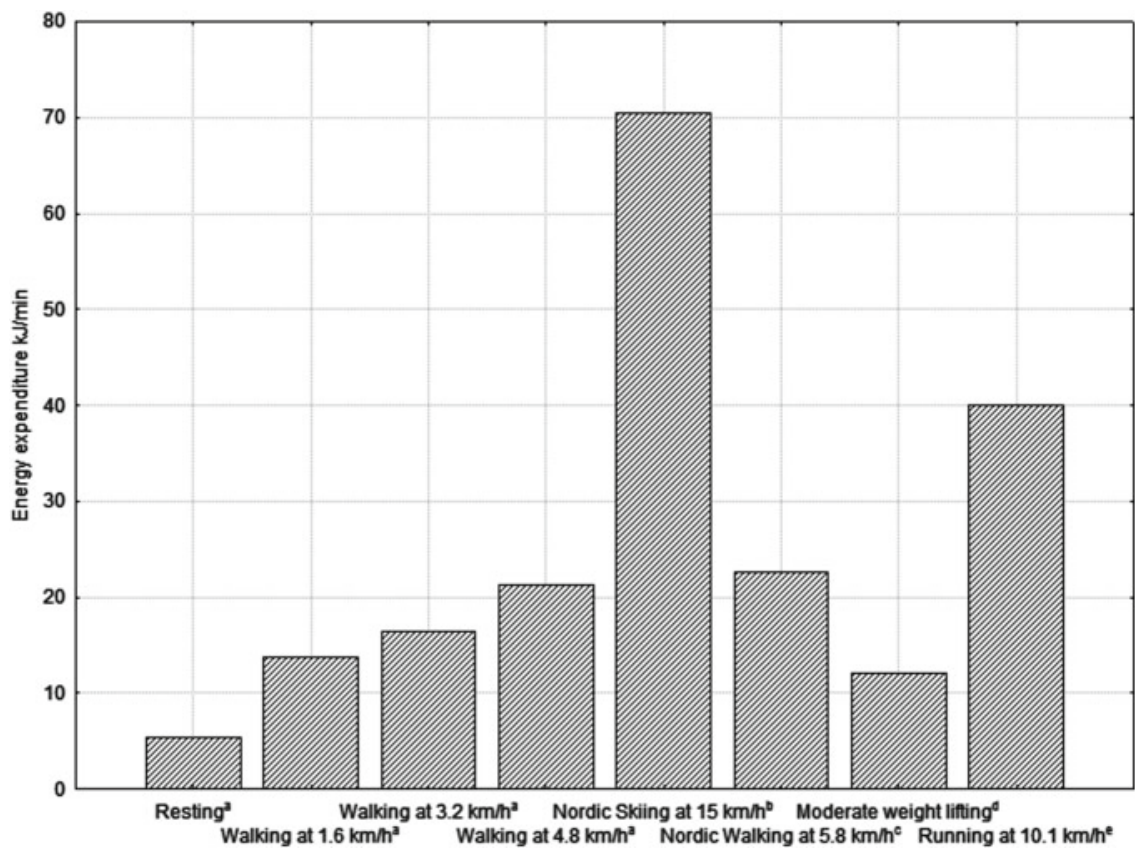

Fig. 3.3 Energy expenditure as a function of specific physical activity. The changes in energy expenditure as a function of physical activity: resting, walking, Nordic skiing, Nordic walking, weight lifting, and running. 'Levine et al. [92], ${ }^{b}$ Niinimaa et al. [93], ${ }^{\mathrm{c}}$ Church et al. [94], ${ }^{\mathrm{d}}$ Morgan et al. [95], ${ }^{\mathrm{e}} \mathrm{Hall}$ et al. [96]. For simplicity only the central values of the population are given

One method of reducing the physical deterioration driven by menopause and/or aging is maintaining a high level of physical fitness, which has clear links to BMI and lipid profiles [11]. Among the most popular physical activities are walking and its variant Nordic-walking (NW), as well as jogging, and cycling. The energy expenditures for walking, Nordic walking, Nordic (cross country) skiing, weight lifting, and running are shown in Fig. 3.3.

Clearly diet too is crucial in minimizing the impact of aging on crucial components of physical wellbeing [13]. While research provides inadequate support to compose a "menopause diet" (other than perhaps recommending high intake of soy), it is extremely important at this time of life to eat a diet high in nutrient density and correspondingly low in energy density. The common pattern of "roller coaster" weight loss and gain that many women have long been on by this time in life can now be especially harmful, as muscle loss is much more likely during weight loss than muscle gain is during weight gain.

Here, we review a number of physiological changes that may be linked to menopause. We have chosen BMI as the most commonly reported indicator related to body fat and weight gain, serum levels of TC, HDL-C, LDL-C, TG, blood pressure, FSH, and LH. These are chosen not only because of their potential public health importance, but also because generally there has been more research on them than on the many others that could be examined.

\section{Body Mass Index}

Among many indices correlating height and weight of a human being, BMI expressed as the ratio of weight in kilogram to height squared in meters $\left(W / H^{2}\right.$, Quetelet index) appears to be the most stable and is the one most commonly used as a rough measure of adiposity. The World Health Organization established a classification for underweight, overweight, and obesity according to BMI (Table 3.1). 
Table 3.1 WHO classification of obesity accordingly to Body Mass Index

\begin{tabular}{ll}
\hline Classification & BMI $\left(\mathrm{kg} / \mathrm{m}^{2}\right)$ \\
\hline Underweight & $<18.50$ \\
Severe thinness & $<16.00$ \\
Moderate thinness & $16.00-16.99$ \\
Mild thinness & $17.00-18.49$ \\
Normal range & $18.50-24.99$ \\
Overweight & $\geq 25.00$ \\
Pre-obese & $25.00-29.99$ \\
Obese & $\geq 30.00$ \\
Obese class I & $30.00-34.99$ \\
Obese class II & $35.00-39.99$ \\
Obese class III & $\geq 40.00$ \\
\hline
\end{tabular}

However, BMI functions poorly as a measure of adiposity in athletic or heavily muscled subjects. For example, an athletic subject with 15-18\% body fat, common among bodybuilders, may be incorrectly classified as obese. Better alternatives exist such as the fat-free mass index (FFMI) (fat free mass $/ \mathrm{ht}^{2}$ ) and the body-fat-mass index (BFMI) (body fat mass $/ \mathrm{ht}^{2}$ ) but these require special equipment and have not been widely enough used in past research to be used in this review.

While a few studies on BMI changes as a function of the menopausal transition indicate that the observed changes are likely due to menopause, per se [14], most find that the commonly seen increase in BMI is probably more related to age increases than menstrual cessation [11], though some argue that declines in levels of exercise are responsible [15]. From a biological perspective, the observed increase in body mass may be driven by a reverse proportional relation between age and resting metabolic rate [16], which may be indirectly influenced by an age-dependent decrease in maximal oxygen uptake capacity $\left(\mathrm{VO}_{2} \max \right)$.

However, in large surveys in France [5] and Italy [17], there was no significant difference in BMI by menopausal status (and thus not by age either). This may serve to remind us that behavioral factors (and the cultural norms linked to them) rather than biological factors may be responsible for many of the differences we report here, especially any that may be linked to weight gain.

Control through exercise. While exercise clearly plays an important role in weight and BMI changes in menopausal and postmenopausal women [18], it is not a one-off activity, but must be continued if these benefits are to be realized.

Regarding the question of which type of exercise best controls BMI, in studies on the impact of Nordic-walking in premenopausal, perimenopausal, and postmenopausal women [11], a clear positive role of moderate endurance training on BMI values was seen across all menopausal groups. Stationary bicycle exercises (6 weeks; three times per week; 30 min per session) also resulted in significant changes in BMI [19]. Similarly, treadmill walking/jogging, stationary cycling, and rowing at least 3-4 days per week for 8 weeks resulted in a significant decrease in BMI in both Caucasian and African American women [20]. Although in all three studies [11, 19, 20] an increase in $\mathrm{VO}_{2}$ max was also observed, the latter [20] does not report a statistically significant increase in resting metabolic rate (RMR). This observation is rather puzzling in light of other studies clearly pointing to a positive correlation between RMR and $\mathrm{VO}_{2} \max$ [21] in premenopausal and postmenopausal women, but the authors claim that the loss of weight during the training program could compensate for the lack of increase in RMR.

Control through diet. Frequency of eating correlates positively with energy intake in both premenopausal and postmenopausal women; however, only in premenopausal women does it correlate with energy expenditure. Thus, it is not surprising that only in postmenopausal women does frequency of eating correlate with percentage body fat [22]. While age appears more important than menopause 
per se, there may be a detrimental interaction between menopause, diet, and exercise, leading to further weight gain during the menopausal period.

In midlife, women tend to make positive behavioral changes, including dietary improvements [23]. Menopausal Spanish women consume more dairy products [24] and Malaysian postmenopausal women were found to consume $6 \%$ less fat than premenopausal women [25].

However, achieving weight loss or even avoiding gain during the midlife period when menopause typically occurs is challenging. In one group of women 47-52 years old, a 2-year follow-up study showed that only those who decreased food quantity, cut down on fats/sugars, used a commercial weight loss program, and exercised avoided weight gain [26], while others (the majority of whom were attempting to control their weight), gained an average of $1.2 \mathrm{~kg}$. Nevertheless, dietary interventions can be effective in reducing weight and BMI and improving blood lipids in postmenopausal women [27]. In the Women's Healthy Lifestyle Project, among women at an average age of 47 at baseline, behavior change efforts over a 5-year period (during which $35 \%$ became postmenopausal) focused on decreasing intakes of calories and cholesterol and increasing exercise in an attempt to reduce the unfavorable changes typically occurring during menopause [28]. Weight was decreased by $0.1 \mathrm{~kg}$ compared to an increase of $2.4 \mathrm{~kg}$ in the control group.

There has been speculation that consumption of soy, in addition to other benefits, might assist with weight control. One study providing supplementation with $99 \mathrm{mg}$ isoflavones daily for 1 year had no impact on BMI compared with provision of an equal amount of milk protein [29] but another 3-month trial in postmenopausal Caucasian and African American women providing $20 \mathrm{~g}$ soy plus $160 \mathrm{mg}$ of isoflavones daily reduced total and subcutaneous abdominal fat [30]. A 6-month trial in postmenopausal Italian women of a diet very high in soy (referred to below as the "high soy study") resulted in a non-significant decrease in BMI, but adherence to such a profoundly changed diet was not high [31].

\section{Total Cholesterol}

Progress in the medical sciences has allowed us to realize that excess cholesterol in the bloodstream may result in a plaque causing atherosclerosis, a thickening and reduction in flexibility of the arteries, often leading to obstruction in blood flow and hypertension. Although current popular and scientific literature portrays cholesterol as the "bad guy," it plays a vital role in homeostasis (i.e. stable internal environment of an organism). For example, cholesterol moderates cell membrane stability making them less temperature dependent. It is also a crucial factor in steroid hormone production and a major participant in vitamin D biosynthesis which in turn is associated with bone mineral density i.e., it is necessary in the maintenance of strong bones. It also regulates function of neurotransmitters. Thus, the use of drugs that inhibit liver cholesterol production has a detrimental influence on our mental capabilities, including memory function. It has to be stressed that the level of TC in our body does not depend on the amount of cholesterol in the diet but is a function of the types of fat consumed; for example saturated fatty acids stimulate cholesterol synthesis.

Analysis of a variety of epidemiological studies led to the Adult Treatment Panel (ATP) III classification [32], consisting of TC, LDL-C and HDL-C, each with a link to CHD risk (Table 3.2).

An analysis of the current literature reveals slight inconsistencies regarding changes in TC level as a function of the menopausal transition. The vast majority of reports $[33,34]$ indicate that the transition between perimenopause and postmenopause is associated with an increase in TC levels. However, Franklin et al. [33] reported a lack of menopause-induced changes in TC level. This phenomenon may be due to a different analytical approach; in contrast to previous reports, in the latter no adjustment for body mass was made. Since many studies found an increase in fat and body mass, one may assume that these two parameters in turn influence the level of TC. 
Table 3.2 Classification of total cholesterol, LDL cholesterol, and HDL cholesterol accordingly to Adult Treatment Panel III

\begin{tabular}{llllll}
\hline Total cholesterol $(\mathrm{mg} / \mathrm{dL})$ & \multicolumn{2}{l}{ LDL cholesterol $(\mathrm{mg} / \mathrm{dL})$} & \multicolumn{2}{l}{ HDL cholesterol $(\mathrm{mg} / \mathrm{dL})$} \\
\hline & & $<100$ & Optimal & $<40$ & Low \\
$<200$ & Desirable & $100-129$ & Near optimal/above optimal & $40-60$ & Normal \\
$200-239$ & Borderline-high & $130-159$ & Borderline-high & & \\
$\geq 240$ & High & $160-189$ & High & $\geq 60$ & High \\
& & $\geq 190$ & Very high & & \\
\hline
\end{tabular}

Control through exercise. TC levels are lower among subjects with higher aerobic fitness in premenopausal, perimenopausal, and postmenopausal women [11]. Some research suggests that a moderate to significant amount of exercise may be required [11], but the minimal amount of exercise required to induce a decrease in TC levels is at present unknown. In studies performed on 28 subjects on a stationary bicycle, the administration of exercise for 14 min at $55 \%$ of each participant's maximal oxygen consumption resulted in an acute decrease in TC levels among all the participants [35]. Not only endurance but also resistance training appears to be beneficial in lowering TC levels [36]. Given that the menopausal increase in TC levels is linked to both the menopausal transition and the aging process, we assume that the administration of almost any exercise program will decrease TC levels throughout the menopausal transition.

Control through diet. Providing a diet high in monounsaturated fats reduces TC levels irrespective of menopausal status [37]. Dietary interventions to improve cardiac health used to focus on fat intake but there is increasing doubt that this is adequate. For example, in one study of Japanese women in midlife (referred to below as "the Japanese study"), diets with a high glycemic load, although lower in TC, even after controlling for menopausal status and several other variables, were associated with no reduction in total serum cholesterol concentrations [38]. Thus, the focus of dietary recommendations has shifted in recent years to increasing intakes of fruits, vegetables, low-fat dairy products, $n-3$ fatty acids, and dietary fiber [39].

In general, diets rich in isoflavones (found largely in soy beans) are found to improve cardiovascular profiles, reducing TC and LDL-C levels, while having no known adverse effects. A recent systematic review [40] estimates that consumption of soy protein was on average associated with a $5.34 \mathrm{mg} / \mathrm{dL}$, or $2.4 \%$, decrease in TC. This increased to $6.56 \mathrm{mg} / \mathrm{dL}$ with consumption of at least $40 \mathrm{mg} / \mathrm{day}$, possibly important in east Asian diets where $50 \mathrm{mg} / \mathrm{day}$ is commonly consumed [41]. However, in a review of six randomized trials with at least 2 years of follow-up in postmenopausal women, Howard et al. [42] concluded that a reduction in the risk of coronary heart disease occurs when diets achieve at least a $12 \%$ decrease in serum TC. The differences in intake seen in modified Western diets (often less than $1 \mathrm{mg}$ /day) are probably not large enough to make any difference [43]. The high soy study resulted in a non-significant decrease in TC [31].

\section{High Density Lipoprotein Cholesterol}

HDL is synthesized in the liver and small intestine. HDL is composed of different apolipoproteins, including apoA-I, apoC-I, apoC-II, and the enzyme lecithin-cholesterol acyl transferase (LCAT). LCAT converts cholesterol to cholesteryl esters, forming a spherical HDL particle. This cholesterolrich lipoprotein $(H D L-C)$ returns to the liver, where the cholesterol is unloaded. HDL cholesterol (HDL-C) normally makes up 20-30 \% of the total serum cholesterol. HDL-C is often referred to as the "good cholesterol" because epidemiological studies have shown that the level of serum HDL-C is 
reversely proportional to CHD morbidity and mortality, but this protective effect may be lost after menopause. The ATP III panel adjusted the cut-off point for HDL-C cholesterol to $40 \mathrm{mg} / \mathrm{dL}$ for both men and women, indicating that subjects having a cholesterol concentration less than $40 \mathrm{mg} / \mathrm{dL}$ were at higher risk of CHD [44] (Table 3.2).

Some studies have found a significant $[12,34]$ and progressive [45] increase in levels of the protective serum high-density lipoprotein cholesterol during the menopausal process, though one study [46] found a decrease during the 2 years preceding menopause and some [5] have found no change. After the final menstrual period, the level of HDL-C usually begins to decline, often reaching the perimenopausal level [11]. One study found a significant decrease in serum HDL-C level from pre-menopause to postmenopause [47], but hormonal levels, age group and BMI levels had not been adequately controlled for. In particular, it is well known that there is a reverse proportional association between BMI and HDL-C levels [48]. Thus, given the typical menopause-related changes in BMI [49], it is likely that the observed changes in HDL-C levels are menopause-driven.

Control through exercise. Some studies report an increase in HDL-C levels in spite of a lack of exercise [50] in women around perimenopause. Later studies indicated that irrespective of baseline levels [11] and regardless of exercise intensity, HDL-C levels increase in women just before and during menopause [51]. Kemmler et al. [52] found that exercise induced only a non-significant positive change in serum HDL-C levels among postmenopausal women. Similarly, Hagner et al. [11] found that exercise induced significant increases in HDL-C levels in pre-menopause and perimenopause but not in the postmenopause. Cauley et al. [53] also found that 2 years of exercise failed to have an impact on HDL-C levels among postmenopausal women.

Control through diet. Neither a low-fat diet, an exercise program, nor a combination of the two increased HDL-C in one study of middle aged men and postmenopausal women with low baseline HDL-C [54]. The Women's Healthy Lifestyle Project also failed to change HDL-C levels [28]. In Japanese women in midlife, diets with a high glycemic load, though lower in TC were associated with lower serum HDL-C cholesterol concentrations after controlling for menopausal status and other variables [38]. Providing a diet high in monounsaturated fats tends to increase HDL-C irrespective of menopausal status [37]. A recent systematic review [40] concluded that consumption of soy protein is not associated with changes in HDL-C. Similarly, the high soy study resulted in no change in HDL-C [31].

\section{Low-Density Lipoprotein Cholesterol}

LDL-C particles are synthesized in the liver and transport cholesterol molecules to extra-hepatic tissues that require cholesterol, for example for biosynthesis of the steroid hormones. After fusion of LDL-cholesterol with a cell, through a specific binding mechanism LDL-C particles are catabolised and cholesterol is used by the cell.

LDL-C is the main source of artery-clogging plaque. LDL-C concentration in human blood serum has been divided into five specific ranges as a function of health related quality of life (Table 3.2).

Some studies have found a continuous increase in LDL-C levels across pre-menopause, perimenopause [55], and postmenopause [12]. The Chin-Shan Community Cardiovascular Cohort study [56] found an increase in LDL-C in premenopausal and perimenopausal women but a decrease in postmenopausal women. The French study [5] found a significant increase in the prevalence of high LDL and high TC combined during menopause.

Control through exercise. Prabhakaran et al. [57] found that resistance training may improve lipid profiles among premenopausal women but applicability to perimenopausal and postmenopausal 
women is to date unknown. Moderate endurance training does appear to influence lipid profiles, reducing LDL-C levels among premenopausal, perimenopausal, and postmenopausal women [11].

Control through diet. Providing a diet high in monounsaturated fats reduces LDL-C levels irrespective of menopausal status [37]. In the Japanese study, diets with a high glycemic load were associated with higher serum LDL-C concentrations in postmenopausal but not premenopausal women [38].

In a study on the influence of an 8 year low-fat diet in postmenopausal women, a $2.7 \mathrm{mg} / \mathrm{dL}$ reduction in LDL-C levels was observed [42]. However, after 5 years of implementation, The Women's Healthy Lifestyle Project was unable to reduce LDL-C. Nevertheless, the $3.5 \mathrm{mg} / \mathrm{dL}$ increase was significantly less than the $8.9 \mathrm{mg} / \mathrm{dL}$ increase in the control group [28]. Prediger et al. [40] found little evidence that consumption of soy protein was associated with changes in LDL-C. The high soy study resulted in a non-significant reduction in LDL-C [31]. However, it may be that even though diet and exercise each alone have only a minor impact, together they seem able to reduce LDL-C in perimenopausal [58] and postmenopausal women [54].

\section{Serum Triglyceride}

A TG (triacylglycerol) is a molecular comprising one molecule of glycerol and three molecules of fatty acids. TG are the main components of animal fats and vegetable oils. Analogous to cholesterol TG play an important role in elasticity of cell membranes and their depots serve as insulation against cold. The correlations found between serum TG levels and CHD rendered these parameters as risk markers for CHD. For example, TG level $\geq 200 \mathrm{mg} / \mathrm{dL}$ is consonant with an elevated level of atherogenic factors that increase the risk for CHD significantly more than TG alone. These observations were included in ATPIII [32] proposed TG classification, Table 3.3.

Elevation in blood TG levels is a derivative of a variety of factors, which can be divided into two groups. The first group comprises factors related to quality of life i.e., obesity, physical inactivity, tobacco smoking, excess alcohol intake, and high-carbohydrate diet and the second to diseases inducing elevation of TG level, i.e., type 2 diabetes, chronic renal failure, nephrotic syndrome, and genetic factors.

Two studies $[33,59]$ report fairly constant TG levels across the menopausal transition. However, other have found a consistent increase in TG levels along with increases in BMI in women during this period [60]. A large French survey found no increase in obesity with menopause but a significant increase in TG [5]. Aging rather than menopause per se appears to be the main factor involved [12].

Control through exercise. Exercise appears to reduce TG levels, even in postmenopausal women; one study found significant decreases after 2 years of exercise (four sessions per week, 60-70 min per session + two 25-min home training sessions) [52]. Another study obtained decreases after only 10 weeks of aerobic and resistance training [61] and a third after 12 weeks of endurance training [11]. A recent study in young women found that, unlike for young men, they had significant decreases in TG in the immediate post-exercise period $(3 \mathrm{~h})$ independent of exercise intensity [62]. The minimum

Table 3.3 Triglyceride categories accordingly to Adult Treatment Panel III

\begin{tabular}{ll}
\hline Triglyceride category & ATP III levels $(\mathrm{mg} / \mathrm{dL})$ \\
\hline Normal triglycerides & $<150$ \\
Borderline-high triglycerides & $150-199$ \\
High triglycerides & $200-499$ \\
Very high triglycerides & $\geq 500$ \\
\hline
\end{tabular}


required exercise level to decrease TG levels, especially during the menopausal transition, is at present unknown.

Control through diet. The Women's Healthy Lifestyle Project was unable to reduce TG but the $18.2 \mathrm{mg} / \mathrm{dL}$ increase was significantly less than the $29.9 \mathrm{mg} / \mathrm{dL}$ increase in the control group over the 5 -year intervention period [28]. In the Japanese study, diets with a high glycemic load, though lower in fat, were associated with higher serum TG concentrations [38]. This effect was more pronounced in postmenopausal than premenopausal women.

The high soy study resulted in a nonsignificant decrease in serum TG [31]. A recent systematic review [40] concluded that consumption of soy protein is not associated with changes in TG.

\section{Blood Pressure}

The last few decades of study on hypertension related health risk indicated that the specific attention should be given to systolic blood pressure (SBP) changes, since these are the main risk factors for cardiovascular diseases. Extensive analysis of the assonant changes in SBP and diastolic blood pressure (DPB) has revealed specific age dependent correlations between the SPB, DPB, and the mean arterial pressure (MAP). SPB rises continuously to the ninth decade of life. This phenomenon is associated with a congruent two-phase increase in the pulse pressure (PP). In the first phase, DBP rises until the age of about 50 when it may level off for the rest of life or fall later in life.

The Joint National Committee on Prevention, Detection, Evaluation, and Treatment of High Blood Pressure (JNC) report [63] introduced a classification of blood pressure in regards to human health status (Table 3.4).

The French study [5], comparing postmenopausal with perimenopausal women within a relatively narrow age range (average 4 years difference in age), found $14.5 \%$ hypertension in the former compared to $7.4 \%$ in the latter group. Zanchetti et al. [64] also found an increase after controlling for age, BMI, and other factors, but only among women undergoing menopause at a younger age. Another study of 671 women referred for coronary angiography [65] found no statistically significant increase in SBP as a function of the menopausal transition when data were adjusted for age. Similarly, a recent analysis of NHANES data [34] concluded that changes in SBP during the menopausal transition were solely due to age increases (Fig. 3.4). DBP also does not appear to change across the premenopausal, perimenopausal, and postmenopausal transition [56].

Control through exercise. In the French study [5], $46 \%$ of postmenopausal women were sedentary compared to $43 \%$ of perimenopausal women and thus a decline in levels of exercise was unlikely to explain the higher level of hypertension in the former group. An early meta-analysis of the literature on SBP among adult women [66] failed to find any clear impact of aerobic exercise on resting SBP. Bond et al. [67] had similar findings in premenopausal African-American women. However, some

Table 3.4 Blood pressure, systolic blood pressure (SBP) and diastolic blood pressure (DBP) classification according to JNC 7

\begin{tabular}{ll}
\hline SBP/DBP & JNC 7 category \\
\hline$<120 / 80$ & Normal \\
$120-139 / 80-89$ & Prehypertension \\
$\geq 140 / 90$ & Hypertension \\
$140-159 / 90-99$ & Stage 1 hypertension \\
$\geq 160 / 100$ & Stage 2 hypertension \\
\hline
\end{tabular}




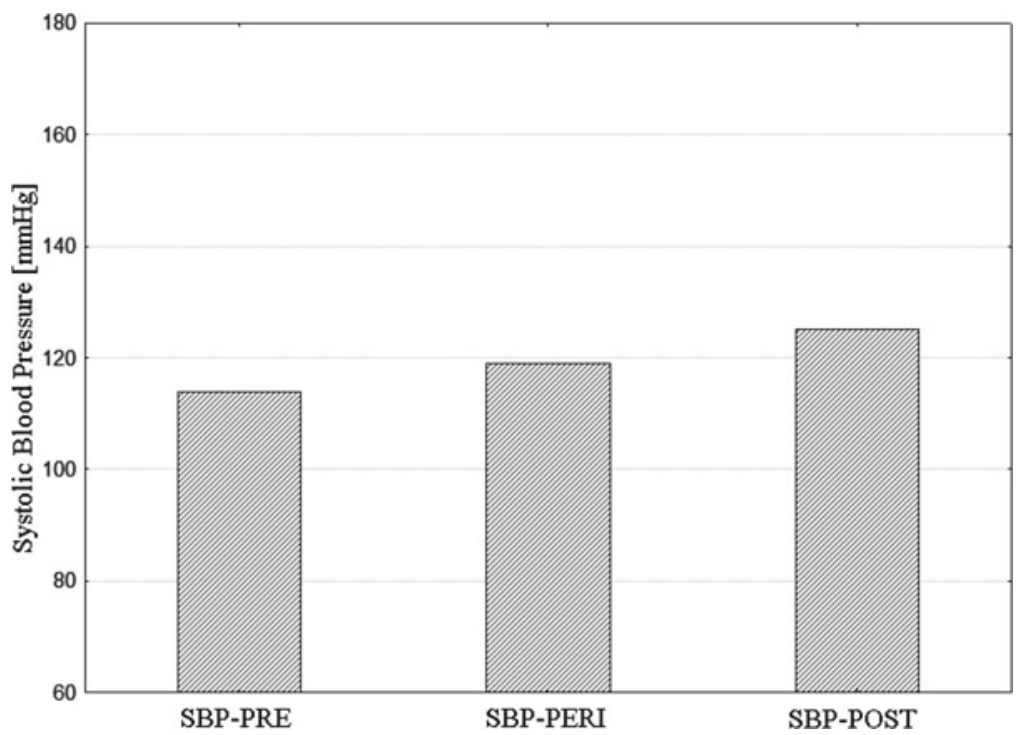

Fig. 3.4 Changes in systolic blood pressure as a function of menopausal status [34]. Relation between Systolic Blood Pressure (SBP) as a function of menopausal status - unpublished results (Wiacek and Zubrzycki). For simplicity only the central values of the population are given. $S B P-P R E$ median value of systolic blood in premenopausal group, $S B P$ $P E R I$ median value of systolic blood pressure in perimenopausal group, SBP-POST median value of systolic blood pressure in postmenopausal group

recent studies do find an impact. For example, Figueroa et al. [68] achieved a reduction in both systolic and diastolic blood pressure in postmenopausal women with 12 weeks of moderate-intensity combined resistance and endurance training. Among women with hypertension, exercise has also proven to have a positive effect in decreasing SBP [69].

Control through diet. In a study by Wing et al. [55], weight increase was positively associated with an increase in SBP. In a 5-year follow-up of perimenopausal women (defined as women aged 47-56), Juntunen et al. [70] similarly concluded that avoiding weight gain via exercise and diet was necessary to prevent postmenopausal hypertension. However, the Women's Healthy Lifestyle Project failed to achieve changes in systolic blood pressure [28]. The high soy study among postmenopausal women also resulted in no change in blood pressure [31].

\section{Luteinizing Hormone}

LH is produced by the anterior pituitary, stimulating in females development of the corpus luteum, a structure formed from tissues of ruptured ovarian follicles. Along with other hormones, including FSH, it takes part in the regulation of the menstrual cycle. Its highest concentration is apparently during the ovulatory phase.

One study reported that only age seemed to be involved [71] and another [72] concluded that menopause alone was responsible for changes in LH levels. However, over the past decade, most studies have suggested that both age and menopause cause an increase in LH levels [12], the study performed on women aged 35-60 encompassed in NHANES III and NHANES 1999-2002 [34] found that $\mathrm{LH}$ increased in a similar fashion in perimenopausal as in postmenopausal women. Thus, more 
research is needed to determine whether the LH increase is driven by a menopause per se, the aging process, or both.

Control through exercise. It has been shown that LH pulsatility-driven amenorrhea occurs among female subjects engaging in a variety of intensive sports, including running and cycling, or in ballet [73]. This phenomenon may be linked with exercise-driven energy depletion-induced amenorrhea congruent with the level of physical fitness leading to metabolic stress manifested by lower SBP, higher $\mathrm{VO}_{2} \max$, lower TC and LDL-C levels, and higher HDL-C levels [23].

Control through diet. During the last two decades, attention has turned towards soy isoflavones as a means of suppression of LH mid-cycle surges among premenopausal women [74]. Though some research did not find soy per se to be very effective [75], a recent trial found that genistein, making up about half of the isoflavones found in soy, with a single daily dose of $30 \mathrm{mg}$, did reduce the frequency and duration of hot flashes [4].

Among the variety of dietary approaches for controlling LH levels in menopausal women, the use of herbal ingredients such as dandelion, ginkgo, ginseng, raspberry, wild yam, black cohosh, phytoestrogens from soy, red clover, flax, and dong quai has become popular. However, none of these has withstood scientific scrutiny [76].

\section{Follicle Stimulating Hormone}

FSH is a glycoprotein gonadotropin secreted by the anterior pituitary in response to gonadotropinreleasing hormone. FSH is primarily responsible for stimulating growth of the ovarian follicle.

In French women 45-55 years of age, serum FSH was 7 IU/L in early perimenopause, 35.9 IU/L in late perimenopause, and 47.8 IU/L in postmenopause [5]. The Melbourne Women's MidLife Health Project study found that the level of FSH begins to rise around 2 years before the final menstrual period [77]. An extensive study comprising four cohorts in TERMIN [78], the Melbourne Women's Midlife Health Project (MWMHP) [79], the Seattle Midlife Women's Health Study (SMWHS) [80], and the Study of Women's Health Across the Nation (SWAN) [81] all reported stronger coupling between FSH concentration and the late menopausal transition than the early menopausal transition. They also revealed a continuous increase in FSH levels across postmenopause up to the level of about $40 \mathrm{IU} / \mathrm{L}$. Notwithstanding the clear-cut changes in FSH levels as a function of the menopause, FSH level is of negligible diagnostic value $\mathrm{i}$ [82].

Control through exercise. At present, only a handful of studies have reported on changes in FSH levels as a function of exercise in premenopausal and postmenopausal women and none of them have focused on perimenopause. A study of exercise and FSH levels in premenopausal women of about 26 years of age found an exercise-induced decrease in FSH levels, but only at the $90 \%$ confidence interval [83]. A study on 50 sedentary Brazilian postmenopausal women had a similar finding [84]; 16-week resistance training resulted in a statistically significant decrease in FSH levels at $\mathrm{P}<0.001$. No significant changes were seen in BMI, muscle mass or fat percentage. However, Trevisan et al. [85] found no impact of resistance training on FSH levels in postmenopausal women. Aerobic training also proved to be an inefficient means of decreasing FSH levels in postmenopausal women, vide the study by Cardoso et al. [86].

Control through diet. Among the handful of studies on this subject is a report [87] indicating no change in FSH activity as a function of a galactose-rich diet in perimenopausal women. A study on supplementation with soy and wheat in postmenopausal women found a decrease in serum FSH in the wheat flour group compared with the soy group [88]. 
Table 3.5 Literature-derived relationships between menopausal-transition driven changes in Body Mass Index (BMI), Total Cholesterol (TC), Triglyceride levels (TG), High-density lipoprotein levels (HDL-C), Low-density lipoprotein levels (LDL-C), Blood Pressure (BP), Luteinizing Hormone activity (LH), and Follicle Stimulating Hormone activity (FSH), and the potential for controlling such changes through physical exercise or diet

\begin{tabular}{llll}
\hline Parameter & Menopausal transition & Control through exercise & Control through diet \\
\hline BMI & Often increased & Aerobic endurance & Likely/uncertain \\
TC & Increase & Aerobic endurance/resistance & Likely \\
TG & Increase & Aerobic endurance & Uncertain \\
HDL-C & Fluctuation & Aerobic endurance & Uncertain \\
LDL-C & Uncertain & Aerobic endurance & Likely \\
BP & Uncertain & Uncertain & Uncertain \\
LH & Increase & Uncertain & Likely/uncertain \\
FSH & Increase & Likely/uncertain & Uncertain \\
\hline
\end{tabular}

\section{Conclusions}

This analysis of current knowledge on the associations between the menopausal transition and anthropometric and physiological parameters, including BMI, TC, HDL-C, LDL-C, TG, LH, FSH, and blood pressure, focused on evidence regarding the extent to which diet and exercise can modify these associations. In Table 3.5 we summarize our conclusions based on current knowledge of these associations. One may clearly see that in many cases the influence of exercise or diet on the specific parameter, if not unknown, is uncertain. Though it was pointed out many years ago that research on these issues needed to be done, including psychosocial factors, and examining effects in heterogeneous populations, little research of this kind has been done [89]. As a result, there are still serious shortcomings in our knowledge of these relationships, hindering attempts to improve HQoL through specific or tailored diet and/or exercise regimes.

However, we believe that the evidence so far available suggests that an increase in weight and the appearance of obesity should not be viewed as tightly linked either to menopause or aging. Most of the observations suggesting such a link have so far been reported from North America and other societies where diet and exercise behaviors, in turn influenced by cultural, commercial food industry, and other factors amenable to change, are at least partially involved. Thus, many of the negative changes often seen during menopause should not be viewed as inevitable. The maintenance and even strengthening of healthy dietary and exercise habits before, through and even after menopause is feasible [90] and will likely pay off in a healthier and longer-lasting [91] old age among women.

\section{References}

1. Wiacek M, Hagner W, Hagner-Derengowska M, et al. Correlations between postural stability and strength of lower body extremities of women population living in long-term care facilities. Arch Gerontol Geriatr. 2009;48:346-9.

2. Ayers B, Forshaw M, Hunter MS. The impact of attitudes towards the menopause on women's symptom experience: a systematic review. Maturitas. 2010;65:28-36.

3. Rogers A. Human behavior in the social environment. McGraw-Hill Humanities/Social Sciences/Languages. United States; 2005.

4. Evans M, Elliott JG, Sharma P, Berman R, Guthrie N. The effect of synthetic genistein on menopause symptom management in healthy postmenopausal women: a multi-center, randomized, placebo-controlled study. Maturitas. 2011;68:189-96.

5. Tremollieres FA, Pouilles JM, Cauneille C, Ribot C. Coronary heart disease risk factors and menopause: a study in 1684 French women. Atherosclerosis. 1999;142:415-23. 
6. van Poppel MN, Brown WJ. "It's my hormones, doctor"-does physical activity help with menopausal symptoms? Menopause. 2008;15:78-85.

7. Davis CE, Pajak A, Rywik S, Williams DH, Broda G, Pazucha T, et al. Natural menopause and cardiovascular disease risk factors. The Poland and US Collaborative Study on Cardiovascular Disease Epidemiology. Ann Epidemiol. 1994;4:445-8.

8. Akahoshi M, Soda M, Nakashima E, Shimaoka K, Seto S, Yano K. Effects of menopause on trends of serum cholesterol, blood pressure, and body mass index. Circulation. 1996;94:61-6.

9. Bonithon-Kopp C, Scarabin PY, Darne B, Malmejac A, Guize L. Menopause-related changes in lipoproteins and some other cardiovascular risk factors. Int J Epidemiol. 1990;19:42-8.

10. Matthews KA, Wing RR, Kuller LH, Meilahn EN, Plantinga P. Influence of the perimenopause on cardiovascular risk factors and symptoms of middle-aged healthy women. Arch Intern Med. 1994;154:2349-55.

11. Hagner W, Hagner-Derengowska M, Wiacek M, Zubrzycki IZ. Changes in level of VO2max, blood lipids, and waist circumference in the response to moderate endurance training as a function of ovarian aging. Menopause. 2009;16:1009-13.

12. Wiacek M, Hagner W, Zubrzycki IZ. Measures of menopause driven differences in levels of blood lipids, follicle-stimulating hormone, and luteinizing hormone in women aged 35 to 60 years: National Health and Nutrition Examination Survey III and National Health and Nutrition Examination Survey 1999-2002 study. Menopause. 2011;18:60-6.

13. Cuzick J, Glasier A, La Vecchia C, Maraganore DM, Negri E, Rossi M, et al. Perimenopausal risk factors and future health. Hum Reprod Update. 2011;17:706-17.

14. Svendsen OL, Hassager C, Christiansen C. Age- and menopause-associated variations in body composition and fat distribution in healthy women as measured by dual-energy X-ray absorptiometry. Metabolism. 1995;44:369-73.

15. Sternfeld B, Wang H, Quesenberry CP, Abrams B, Everson-Rose SA, Greendale GA, et al. Physical activity and changes in weight and waist circumference in midlife women: findings from the study of women's health across the nation. Am J Epidemiol. 2004;160:912-22.

16. Luhrmann PM, Edelmann-Schafer B, Neuhauser-Berthold M. Changes in resting metabolic rate in an elderly German population: cross-sectional and longitudinal data. J Nutr Health Aging. 2010;14:232-6.

17. Pasquali R, Casimirri F, Pascal G, Tortelli O, Labate AMM, Bertazzo D, et al. Influence of menopause on blood cholesterol levels in women: the role of body composition, fat distribution and hormonal milieu. J Intern Med. 1997;241:195-203.

18. Choquette S, Riesco E, Cormier E, Dion T, Aubertin-Leheudre M, Dionne IJ. Effects of soya isoflavones and exercise on body composition and clinical risk factors of cardiovascular diseases in overweight postmenopausal women: a 6-month double-blind controlled trial. Br J Nutr. 2011;105:1199-209.

19. Dunai A, Novak M, Chung SA, Kayumov L, Keszei A, Levitan R, et al. Moderate exercise and bright light treatment in overweight and obese individuals. Obesity (Silver Spring). 2007;15:1749-57.

20. Santa-Clara H, Szymanski L, Ordille T, Fernhall B. Effects of exercise training on resting metabolic rate in postmenopausal African American and Caucasian women. Metabolism. 2006;55:1358-64.

21. Van Pelt RE, Jones PP, Davy KP, Desouza CA, Tanaka H, Davy BM, et al. Regular exercise and the age-related decline in resting metabolic rate in women. J Clin Endocrinol Metab. 1997;82:3208-12.

22. Yannakoulia M, Melistas L, Solomou E, Yiannakouris N. Association of eating frequency with body fatness in pre- and postmenopausal women. Obesity (Silver Spring). 2007;15:100-6.

23. De Cree C. Comment on health issues for women athletes: exercise-induced amenorrhea. J Clin Endocrinol Metab. 1999;84:4750-1.

24. Ubeda N, Basagoiti M, Alonso-Aperte E, Varela-Moreiras G. Dietary food habits, nutritional status and lifestyle in menopausal women in Spain. Nutr Hosp. 2007;22:313-21.

25. Pon LW, Noor-Aini MY, Ong FB, Adeeb N, Seri SS, Shamsuddin K, et al. Diet, nutritional knowledge and health status of urban middle-aged Malaysian women. Asia Pac J Clin Nutr. 2006;15:388-99.

26. Williams L, Germov J, Young A. Preventing weight gain: a population cohort study of the nature and effectiveness of mid-age women's weight control practices. Int J Obes (Lond). 2007;31:978-86.

27. Abedi P, Lee MHS, Kandiah M, Yassin Z, Shojaeezade D, Hosseini M, et al. Diet intervention to improve cardiovascular risk factors among Iranian postmenopausal women. Nutr Res Pract. 2010;4:522-7.

28. Loucks AB. Energy balance and body composition in sports and exercise. J Sports Sci. 2004;22:1-14.

29. Kok L, Kreijkamp-Kaspers S, Grobbee DE, Lampe JW, van der Schouw YT. Soy isoflavones, body composition, and physical performance. Maturitas. 2005;52:102-10.

30. Christie DR, Grant J, Darnell BE, Chapman VR, Gastaldelli A, Sites CK. Metabolic effects of soy supplementation in postmenopausal Caucasian and African American women: a randomized, placebo-controlled trial. Am J Obstet Gynecol. 2010;203:153.e151-9.

31. Chiechi LM, Secreto G, Vimercati A, Greco P, Venturelli E, Pansini F, et al. The effects of a soy rich diet on serum lipids: the Menfis randomized trial. Maturitas. 2002;41:97-104.

32. Third Report of the National Cholesterol Education Program (NCEP) Expert Panel on Detection, Evaluation, and Treatment of High Blood Cholesterol in Adults (Adult Treatment Panel III). Third Report of the National 
Cholesterol Education Program (NCEP) Expert Panel on detection, evaluation, and treatment of high blood cholesterol in adults (Adult Treatment Panel III) final report. Circulation. 2002;106:3143-421.

33. Franklin RM, Ploutz-Snyder L, Kanaley JA. Longitudinal changes in abdominal fat distribution with menopause. Metabolism. 2009;58:311-5.

34. Wiacek M, Jegal BS, Hagner W, Hagner-Derengowska M, Zubrzycki IZ. Age- and menopause-related differences in physiological factors of health quality in women aged 35-60. Arch Gerontol Geriatr. 2012;54(2):385-90.

35. Lennon DL, Stratman FW, Shrago E, Nagle FJ, Hanson PG, Madden M, et al. Total cholesterol and HDLcholesterol changes during acute, moderate-intensity exercise in men and women. Metabolism. 1983;32:244-9.

36. Boyden TW, Pamenter RW, Going SB, Lohman TG, Hall MC, Houtkooper LB, et al. Resistance exercise training is associated with decreases in serum low-density lipoprotein cholesterol levels in premenopausal women. Arch Intern Med. 1993;153:97-100.

37. Mata P, Garrido JA, Ordovas JM, Blazquez E, Alvarezsala LA, Rubio MJ, et al. Effect of dietary monounsaturated fatty acids on plasma lipoproteins and apolipoproteins in women. Am J Clin Nutr. 1992;56:77-83.

38. Montoye HJ, Mikkelsen WM, Block WD, Gayle R. Relationship of oxygen uptake capacity, serum uric acid and glucose tolerance in males and females, age 10-69. Am J Epidemiol. 1978;108:274-82.

39. Tobita Y, Otaki H, Kusaka Y, Iki M, Kajita E, Sato K. [A cross-sectional analysis on relationships between maximum oxygen uptake and risk factors for cardiovascular diseases]. Sangyo Eiseigaku Zasshi. 1995;37:409-15.

40. Prediger CCD, Olinto MTA, Nacul LC, Ziegler DR, Pattussi MP. Effects of soy protein containing isoflavones on women's lipid profile: a meta-analysis. Rev Nutr. 2011;24:161-72.

41. Somekawa Y, Chiguchi M, Ishibashi T, Aso T. Soy intake related to menopausal symptoms, serum lipids, and bone mineral density in postmenopausal Japanese women. Obstet Gynecol. 2001;97:109-15.

42. Howard BV, Van Horn L, Hsia J, Manson JE, Stefanick ML, Wassertheil-Smoller S, et al. Low-fat dietary pattern and risk of cardiovascular disease: the Women's Health Initiative Randomized Controlled Dietary Modification Trial. JAMA. 2006;295:655-66.

43. Kreijkamp-Kaspers S, Kok L, Bots ML, Grobbee DE, van der Schouw YT. Dietary phytoestrogens and plasma lipids in Dutch postmenopausal women; a cross-sectional study. Atherosclerosis. 2005;178:95-100.

44. National Cholesterol Education Program. Third Report of the Expert Panel on detection, evaluation, and treatment of high blood cholesterol in adults (ATP III Final Report). Bethesda, MD; 2002.

45. Kim CJ, Kim TH, Ryu WS, Ryoo UH. Influence of menopause on high density lipoprotein-cholesterol and lipids. J Korean Med Sci. 2000;15:380-6.

46. Jensen J, Nilas L, Christiansen C. Influence of menopause on serum lipids and lipoproteins. Maturitas. 1990;12:321-31.

47. Nerbrand C, Lidfeldt J, Nyberg P, Schersten B, Samsioe G. Serum lipids and lipoproteins in relation to endogenous and exogenous female sex steroids and age. The women's health in the lund area (WHILA) study. Maturitas. 2004;48:161-9.

48. Ernst ND, Obarzanek E, Clark MB, Briefel RR, Brown CD, Donato K. Cardiovascular health risks related to overweight. J Am Diet Assoc. 1997;97:S47-51.

49. McNeil CJ, Vandervoort AA, Rice CL. Peripheral impairments cause a progressive age-related loss of strength and velocity-dependent power in the dorsiflexors. J Appl Physiol. 2007;102:1962-8.

50. Brownell KD, Bachorik PS, Ayerle RS. Changes in plasma lipid and lipoprotein levels in men and women after a program of moderate exercise. Circulation. 1982;65:477-84.

51. Spate-Douglas T, Keyser RE. Exercise intensity: its effect on the high-density lipoprotein profile. Arch Phys Med Rehabil. 1999;80:691-5.

52. Kemmler W, Lauber D, Weineck J, Hensen J, Kalender W, Engelke K. Benefits of 2 years of intense exercise on bone density, physical fitness, and blood lipids in early postmenopausal osteopenic women: results of the Erlangen Fitness Osteoporosis Prevention Study (EFOPS). Arch Intern Med. 2004;164:1084-91.

53. Cauley JA, Kriska AM, LaPorte RE, Sandler RB, Pambianco G. A two year randomized exercise trial in older women: effects on HDL-cholesterol. Atherosclerosis. 1987;66:247-58.

54. Stefanick ML, Mackey S, Sheehan M, Ellsworth N, Haskell WL, Wood PD. Effects of diet and exercise in men and postmenopausal women with low levels of HDL cholesterol and high levels of LDL cholesterol. N Engl J Med. 1998;339:12-20.

55. Wing RR, Matthews KA, Kuller LH, Meilahn EN, Plantinga PL. Weight gain at the time of menopause. Arch Intern Med. 1991;151:97-102.

56. Torng PL, Su TC, Sung FC, Chien KL, Huang SC, Chow SN, et al. Effects of menopause on intraindividual changes in serum lipids, blood pressure, and body weight - the Chin-Shan Community Cardiovascular Cohort study. Atherosclerosis. 2002;161:409-15.

57. Prabhakaran B, Dowling EA, Branch JD, Swain DP, Leutholtz BC. Effect of 14 weeks of resistance training on lipid profile and body fat percentage in premenopausal women. Br J Sports Med. 1999;33:190-5.

58. Wildman RP, Schott LL, Brockwell S, Kuller LH, Sutton-Tyrrell K. A dietary and exercise intervention slows menopause-associated progression of subclinical atherosclerosis as measured by intima-media thickness of the carotid arteries. J Am Coll Cardiol. 2004;44:579-85. 
59. Cho EJ, Min YJ, Oh MS, Kwon JE, Kim JE, Lee WS, et al. Effects of the transition from premenopause to postmenopause on lipids and lipoproteins: quantification and related parameters. Korean J Intern Med. 2011;26:47-53.

60. Sundquist J, Winkleby MA, Pudaric S. Cardiovascular disease risk factors among older black, Mexican-American, and white women and men: an analysis of NHANES III, 1988-1994. Third National Health and Nutrition Examination Survey. J Am Geriatr Soc. 2001;49:109-16.

61. Fahlman MM, Boardley D, Lambert CP, Flynn MG. Effects of endurance training and resistance training on plasma lipoprotein profiles in elderly women. J Gerontol A Biol Sci Med Sci. 2002;57:B54-60.

62. Henderson GC, Krauss RM, Fattor JA, Faghihnia N, Luke-Zeitoun M, Brooks GA. Plasma triglyceride concentrations are rapidly reduced following individual bouts of endurance exercise in women. Eur J Appl Physiol. 2010;109:721-30.

63. Chobanian AV, Bakris GL, Black HR, Cushman WC, Green LA, Izzo JL, Jr., et al. The Seventh Report of the Joint National Committee on prevention, detection, evaluation, and treatment of high blood pressure: the JNC 7 report. JAMA. 2003;289:2560-72.

64. Zanchetti A, Facchetti R, Cesana GC, Modena MG, Pirrelli A, Sega R, et al. Menopause-related blood pressure increase and its relationship to age and body mass index: the SIMONA epidemiological study. J Hypertens. 2005;23:2269-76.

65. Gierach GL, Johnson BD, Merz CNB, Kelsey SF, Bittner V, Olson MB, et al. Hypertension, menopause, artery disease risk in the and coronary women's ischemia syndrome evaluation (WISE) study. J Am Coll Cardiol. 2006;47:50s-8.

66. Kelley GA, Kelley KS. Aerobic exercise and resting blood pressure in women: a meta-analytic review of controlled clinical trials. J Womens Health Gend Based Med. 1999;8:787-803.

67. Bond V, Millis RM, Adams RG, Oke LM, Enweze L, Blakely R, et al. Attenuation of exaggerated exercise blood pressure response in African-American women by regular aerobic physical activity. Ethn Dis. 2005;15:S5-10-3.

68. Figueroa A, Park SY, Seo DY, Sanchez-Gonzalez MA, Baek YH. Combined resistance and endurance exercise training improves arterial stiffness, blood pressure, and muscle strength in postmenopausal women. Menopause. 2011;18:980-4.

69. Hagberg JM, Brown MD. Does exercise training play a role in the treatment of essential hypertension? J Cardiovasc Risk. 1995;2:296-302.

70. Juntunen M, Niskanen L, Saarelainen J, Tuppurainen M, Saarikoski S, Honkanen R. Changes in body weight and onset of hypertension in perimenopausal women. J Hum Hypertens. 2003;17:775-9.

71. MacNaughton J, Banah M, McCloud P, Hee J, Burger H. Age related changes in follicle stimulating hormone, luteinizing hormone, oestradiol and immunoreactive inhibin in women of reproductive age. Clin Endocrinol (Oxf). 1992;36:339-45.

72. Klein NA, Battaglia DE, Fujimoto VY, Davis GS, Bremner WJ, Soules MR. Reproductive aging: accelerated ovarian follicular development associated with a monotropic follicle-stimulating hormone rise in normal older women. J Clin Endocrinol Metab. 1996;81:1038-45.

73. Warren MP. Health issues for women athletes: exercise-induced amenorrhea. J Clin Endocrinol Metab. 1999;84:1892-6.

74. Cassidy A, Bingham S, Setchell KD. Biological effects of a diet of soy protein rich in isoflavones on the menstrual cycle of premenopausal women. Am J Clin Nutr. 1994;60:333-40.

75. Duncan AM, Merz BE, Xu X, Nagel TC, Phipps WR, Kurzer MS. Soy isoflavones exert modest hormonal effects in premenopausal women. J Clin Endocrinol Metab. 1999;84:192-7.

76. Wylie-Rosett J. Menopause, micronutrients, and hormone therapy. Am J Clin Nutr. 2005;81:1223S-31.

77. Burger HG, Cahir N, Robertson DM, Groome NP, Dudley E, Green A, et al. Serum inhibins A and B fall differentially as FSH rises in perimenopausal women. Clin Endocrinol (Oxf). 1998;48:809-13.

78. Treloar AE, Boynton RE, Behn BG, Brown BW. Variation of the human menstrual cycle through reproductive life. Int J Fertil. 1967;12:77-126.

79. Dennerstein L, Dudley EC, Hopper JL, Guthrie JR, Burger HG. A prospective population-based study of menopausal symptoms. Obstet Gynecol. 2000;96:351-8.

80. Mitchell ES, Woods NF, Mariella A. Three stages of the menopausal transition from the Seattle midlife women's health study: toward a more precise definition. Menopause. 2000;7:334-49.

81. Sowers M, Crawford S, Sternfeld B, Morgenstein D, Gold E, Greendale G, et al. SWAN: a multicenter, multiethnic, community-based cohort study of women and the menopausal transition. In: Lobo R, Kelsey J, Marcus R, editors. Menopause: biology and pathobiology. San Diego, CA: Academic; 2000. p. 175-88.

82. Burger HG. Diagnostic role of follicle-stimulating hormone (FSH) measurements during the menopausal transitionan analysis of FSH, oestradiol and inhibin. Eur J Endocrinol. 1994;130:38-42.

83. Bonen A, Ling WY, MacIntyre KP, Neil R, McGrail JC, Belcastro AN. Effects of exercise on the serum concentrations of FSH, LH, progesterone, and estradiol. Eur J Appl Physiol Occup Physiol. 1979;42:15-23. 
84. Orsatti FL, Nahas EA, Maesta N, Nahas-Neto J, Burini RC. Plasma hormones, muscle mass and strength in resistance-trained postmenopausal women. Maturitas. 2008;59:394-404.

85. Trevisan M, Burini R. Resting metabolism of post-menopause women submitted to a training program with weights (hypertrophy). Rev Bras Med Esporte. 2007;13:116-9.

86. Ardoso CG, Jr., Rosas FC, Oneda B, Labes E, Tinucci T, Abrahao SB, et al. Aerobic training abolishes ambulatory blood pressure increase induced by estrogen therapy: a double blind randomized clinical trial. Maturitas. 2011;69:189-94.

87. Cooper GS, Baird DD, Darden FR. Measures of menopausal status in relation to demographic, reproductive, and behavioral characteristics in a population-based study of women aged 35-49 years. Am J Epidemiol. 2001;153:1159-65.

88. Murkies AL, Lombard C, Strauss BJ, Wilcox G, Burger HG, Morton MS. Dietary flour supplementation decreases post-menopausal hot flushes: effect of soy and wheat. Maturitas. 1995;21:189-95.

89. Kuller LH, Meilahn EN, Cauley JA, Gutai JP, Matthews KA. Epidemiologic studies of menopause: changes in risk factors and disease. Exp Gerontol. 1994;29:495-509.

90. Beasley JM, Schenk JM, Ludman E, Lampe JW, Reed SD, Grothaus L, et al. Brief telephone intervention increases soy intake in peri- and postmenopausal US women: the herbal alternatives trial (HALT). J Am Diet Assoc. 2010;110:1189-97.

91. van den Brandt PA. The impact of a Mediterranean diet and healthy lifestyle on premature mortality in men and women. Am J Clin Nutr. 2011;94:913-20.

92. Levine JA, Schleusner SJ, Jensen MD. Energy expenditure of nonexercise activity. Am J Clin Nutr. 2000;72:1451-4.

93. Niinimaa V, Shephard RJ, Dyon M. Determinations of performance and mechanical efficiency in nordic skiing. Br J Sports Med. 1979;13:62-5.

94. Church TS, Earnest CP, Morss GM. Field testing of physiological responses associated with nordic walking. Res Q Exerc Sport. 2002;73:296-300.

95. Morgan B, Woodruff SJ, Tiidus MP. Aerobic energy expenditure during recreational weight training in females and males. J Sport Sci Med. 2003;2:117-22.

96. Hall C, Figueroa A, Fernhall B, Kanaley JA. Energy expenditure of walking and running: comparison with prediction equations. Med Sci Sports Exerc. 2004;36:2128-34. 